\title{
Research on Application of Children's Behavior Pattern in Toy Design
}

\author{
Fang Li \\ Suzhou Art and Design Technology Institute \\ Suzhou, China
}

\begin{abstract}
Provide reference for relevant children's toy product design and application through analysis on necessity of toy pattern and statement of design key point of children's behavior in toy design from the five aspects of children's motion behavior, gender behavior, prosocial behavior, cognitive behavior and imitation behavior.
\end{abstract}

Keywords - behavior pattern; children's toy design; physical needs ; psychological needs

\section{INTRODUCTION}

With improvement of people's living standard, children's toy design is no longer a simple thing, but an artificiality designed from analysis on observation of toy pattern, research of children psychological and physical needs, imitation of children's service environment and exploration of children's consumption behavior. Children's toy design is closely related to children's growth and can bring comfortable, happy, healthy and reasonable life style to children's life and growth.

\section{NECESSITY OF CHILDREN'S BEHAVIOR PATTERN IN CHILDREN'S TOY DESIGN}

\section{A. Children's Toy Design Based on Behavior Pattern Should Conform to Market Requirement}

With increase of family's economic income and change of home education pattern, children's product market has gradually developed and expanded. The market starts to falls into categories of daily necessities, furniture and toys which are relevant products of children. Parents pay more and more attention to children's growth, putting forward higher requirements for function, modeling, material and color of children's toy. When people buy products, their attention focuses on whether the product conforms to children's physical and psychological development and behavior pattern, and the product's safety, entertainment, education, experience and distinctness. These attentions bring huge opportunities into the market. This kind of focus effect motivates development of children's toy market and conforms to needs of consumer and market.

\section{B. Children's Toy Design Based on Behavior Pattern Should} Conform to Physical and Mental Development of Children

Children in different phases have different mental and physical development, necessarily resulting in different behavior pattern. Difference in toy pattern necessarily results in different children toys. Display of children's motion behavior, imitation behavior, cognitive behavior, spontaneous behavior and social behavior in children's toy design conforms to activity, intelligence and personality characteristics in different phases of children's mental and physical development and conforms to requirements of comprehensive development of children's mind and body. Action is an important sign of children's mental and physical development and it is also the basis of development of children's other skills. Development of children's motion behavior is under combined effect of brain, nervous system and muscle. Especially in infantile period, children's action development and mental development are positively proportional. Action development can reflect mental development. What's more, children's action development is not a temporary process, but a continuous and periodical development process.

\section{Children's Toy Design Based on Behavior Pattern Should Conform to Safety Requirement for Children's Growth}

It is basic standard for raising a child to guarantee children's healthy body, normal growing and avoiding harm. It is both the primary question of children's toy design and children's safety problem. Safety of children's toy is not only displayed in physical dimension, structural strength, material, weight and other physical and chemical indexes. We should also consider whether operation method and process will influence children's safety and whether use behavior of product conforms to children's behavior pattern.

\section{CHILDREN'S TOY DESIGN BASED ON CHILDREN'S RELEVANT BEHAVIOR PATTERN}

Children's toy design must conform to features of toy pattern and combine with children's mental and emotional needs to make it conform to change of behavior pattern in the process of product usage for children and to promote healthy development of children's body and mind. Take toy pattern as the start point for life pattern and consider children's mind and body in specific operations and action behaviors to determine key elements in product. Then, determine specific design elements of modeling, material, color, dimension and craft needed by the product. Put design emphasis on research of children's behavior[1]. 


\section{A. Children's Toy Design Based on Action Behavior- "Action"}

Motion behavior mainly refers to change of action capacity in children's action development process. Motion behavior features displayed in change of various capacities are key points of children's product design. Children's motion behavior is constantly changing with their growing up. As to category of action, firstly major and great movement appears, like pursuit of seeing, turning head, turning over, sitting and crawling, standing, walking, jumping and so on, then fine movement appears, like grasping, releasing, operation by both hands and other hand operations. Each motion behavior is display of children's mind and body[2]. Product design should pay attention to motion behavior in different age phases. Only by doing so, can we design toys suitable for children at a certain age.

Take fine movement of infantile children as an instance. Among children's overall action skill development, stretching out hand to obtain things and grasping play the most important role in infant's cognitive development. They perceive physical features of objects through stretching out hands to hold the object, like shape, soft or hard, sound and so on to obtain object's spatial feature, like direction, distance and so on[3]. For instance, three children's toy products can train children's fine movement, but they aim at understanding of children's fine movement towards toys in different age phases. In terms of function, they provide the three training forms of change of grasp volume size, change of shape and change of stringing decoration to progressively train fine movement of children's hand. For infants, it is pretty difficult to put object accurately into the hole. Accomplishment of this action can not only perfect action system, but also develop and satisfy children's curiosity in world sense. It is also the most important design element considered in fine movement toy design. All three products choose safe and environmental friendly beech as their material and colors with high saturation and high purity.

\section{B. Children's Toy Design Based on Cognitive Behavior- "Recognition"}

Cognitive behavior refers to all behaviors of perceiving and understanding the objective world in their growing process. Cognitive behavior capacity includes sensory recognition, image recognition, color recognition, geometrical shape recognition, language recognition, graphics space recognition and so on. Appearance of cognitive behavior derives from parents' requirements on children's physical, mental, intelligence and learning capacity development[4].

Take infants as an instance. Cognitive behavior of infants is mainly displayed in cognitive experience. Infants' sensory perception experiences firstly instinctive unconditioned reflex, passive sensorimotor phase, and then active sensorimotor phase. During this phase, infants should be able to clearly identify various colors and shapes, understand the concept of space, judge size and distance of an object and strength of sound, learn numbers, letters and pictures and other relevant knowledge abilities. Design of children's toy in this phase totally conforms to law of children's cognitive capacity development. We should start from simple to complex and from easy to difficult and be clear of children's cognitive features in each phase. For instance, modeling of toy should be simple geometry, bright and lively color and functions which can train children's cognitive capacity and help children recognize letters, pictures, colors, numbers and size should be selected. At the same time, we can put building blocks in corresponding shapes and colors into corresponding wooden box to train children's action ability, classification recognition ability and sense of achievement in study.

\section{Children's Toy Design Based on Social Behavior- "Association"}

Prosoical behavior refers to all actions conforming to social prospect and beneficial to other people, community or society, mainly including cooperation, sharing, helping others, comforting, donate, humility and so on[5]. Prosocial behavior is displayed in infantile period. For instance, infants like smiling faces and smile to people who smile to them, instinctive cooperation response, and babble exchange speaking and response to companion. Children around 1 year old have game sense and they can share toys with each other and imitate each other. Children's cooperation behavior officially develops after 2 years old and develops rapidly. In this period, children begin to look for peers with the same theme as playmates. In preschool period, with development of adjustment ability on attentiveness, young children gradually contact with companion of the same age, especially in game situation. In preschool period, with increase of age, children become more and more adaptive to other people's mental features and yearn for dealing with things and keeping friendship in social behavior pattern more[6].

Take Hape Boast Rilla ball as an instance. Combing bend and straight railway, auxiliary parts of building blocks and accelerator, and ingenuity and whim, they create ever changing ball movement locus. Product function mainly lies in children's natural learning of significance of communication and cooperation in playing. Meccano product can mostly reflect children's prosocial behavior. Product design emphasizes on module design. Add kits of different sizes and series for different track routes and gradually expand toys. It supports playing alone and playing together. Over development type has no limit on children's playing, allowing them to try, explore and think constantly in formation and assembling process. Thus, children's logical thinking ability, spacial imagination and creation can be promoted infinitely. Enjoy fun of creativity of thinking in the safest environment. The product adopts environmental friendly beech and rubber wood as its material, abundant colors and outstanding details. It emphasizes on the process of children's playing instead of result in children's toy design. It passes children's behavior pattern to children in the process.

\section{Children's Toy Design Based on Gender Behavior- "Difference"}

Gender role refers to the combination of male or female value, personality characteristics and behavioral pattern formed in certain social culture and it is a kind of social behavioral pattern endowed according to gender by society[7]. With enhancement of sexual sense, boys and girls have different character orientations. They start to prefer activity 
and altitude connected with their gender roles. Boys display more masculinity and extrovert, showing great curiosity in the outside world. Girls are relatively introvert and quiet[8].

Gender behavior has key influence on children's toy design. Due to gender difference, user groups of different gender have different preference in product design and different requirements for color, modeling, function, form, size and so on. Gender difference has explicit distinctions in children's toy, for instance, Barbie doll and transformers are two representative products. When furnishing children's room, parents will consider children's gender characters in purchasing furniture, toys, bedding and choosing decorative style. In terms of function, girls prefer baby dolls and female role play toy products which can train their dressing up, orderliness and aestheticism, while boys prefer cars, transformers and building blocks which can train their logic, space sense and challenge sense. In terms of color, girls prefer warm color series while boys prefer cool color series. Mentally, girls hope to realize princess dream in toys while boys hope to be heroes. Due to difference in gender role, there is also difference in features of beloved products of boys and girls. Therefore, we should consider user gender of product when designing toys to provide better choices for parents in selecting products and to produce products which can better serve children of different gender.

\section{E. Children's Toy Design Based on Imitation Behavior- "Imitation"}

Development of children's action, language, drawing and techniques needs to be realized through imitation. Imitation plays an important role in development of social cognition and is an important means for children to learn skills and accumulate experience. At the age of around 2, children complete transition from direct imitation to deferred imitation. Improvement of cognitive ability not only derives from imitation, but also further controls imitation[9]. Development of movement and cognition constitutes the basis of development of children's imitation. Infants' primary imitation ability is limited. When getting familiar with imitation behavior, imitation of new things and new behaviors will appear. Imitation ability is not continuous, but periodical. When children master a lot of new abilities, imitation ability will decrease greatly. Children play a certain role, perform certain scenes and exercise correct behaviors in playing role play products. Babies can learn some basic skills through training according to fixed model of product design. "Similarity" of imitation behavior should be displayed in product design. Children use presentations of things in their brain, train their living skills under development, gain joy and prompt further development of basic living skills in imitation behavior. Children engaging in imitation behavior do not aim at achieving any clear purpose, but emphasize on the process of imitation process and learning of skills and accumulation of experience in imitation process.

In terms of children imitating dining behavior, due to limitation of eating surroundings, it is impossible to have children repeat dining behavior. In order to make children better grasp dining skills and develop good dietary habits, we design relevant toy products of dining behavior which support repeated usage. In the process of product design, we should consider children's behavior pattern of operating products, their way of grabbing spoons and chopsticks and possible dangerous situations during dining. It is obvious that children need to learn many things during the process of growing up. At the same time, corresponding imitation behavior toy design is needed. We must consider that design of this kind of toy products should start with children's imitation behavior in the process of design. The purpose is to have children learn basic living skills in operational process, train their action ability, ability of multifariously using dining tools and relevant behavior pattern, and guide them in having good living habits. Product material should be environmental friendly and safe. Product color should be able to display and restore genuine environment to a higher degree. We should not just regard these playing house products as toys. Instead, we should regard them as children's growth training products, attach importance to them and research them.

\section{CONCLUSION}

Research on children's toy design is the primary way to focus on children's health and growth and the main carrier of toy model, including whether toy products can correctly lead healthy development of children's body and mind. In the process of product design, we should start from children's behavior pattern to research action behavior, gender behavior, prosocial behavior, cognitive behavior and imitation behavior of different age phases and consider children's psychological environment and game atmosphere in a multidisciplinary and multi-angle way. Product design should conform to sight, listening, touch and other senses and cognitive capacity development requirement and so on. We must fight for the market prospect of safe and healthy children's toy design.

\section{REFERENCES}

[1] Shen Yan. Research on Children's Toy Design Based on Behavior Pattern[D]. Jiangnan University, 2009.

[2] Zhao Dongxia. Infants' Toy Design Based on Action Development[J]. Art and Design, 2009 (3) : 156-157.

[3] Li Yan and Zhao Yan. Preschool Children's Development Psychology[M]. East China Normal University Press. 2008.

[4] Zhou Hong. Developmental Psychology[M]. China Light Industry Press, 2013.

[5] Beijing Municipal Commission of Education. Early Childhood Education[M]. Beijing Normal University Press, 2010.

[6] Wang Meifang. Development Features and Education of Preschool Children's Prosocial Behavior[J]. Shandong Normal University Journal, 2000 (4) : 74-76.

[7] Shen Yan. Children's Gender Role Behavior and Toy Design[J]. Great Master, 2012 (2) : 22-22.

[8] Li Na. Toy Psychology and Children's Park Design[D]. Master's Thesis of Hunan University, 2008.

[9] Lin Yonghai. Children's Imitation and Its Education Value[J]. Children and Education Psychology, 1987 (6) :9-11. 